CORRECTIONS

\title{
Aristolochic acid nephropathy
}

In the print version of this Editorial (BMJ 2012;344:e4000, doi:10.1136/bmj.e4000) we inadvertently used an incorrect image. We thought we were showing Aristolochia clematitis as this was how the plant was described by Science Photo Library, which supplied the image. Science Photo Library has since confirmed to us that its supplied image was not of Aristolochia clematitis. The real Aristolochia clematitis is shown below. $\Downarrow$

Cite this as: BMJ 2012;345:e4993

๑ BMJ Publishing Group Ltd 2012 
Figure

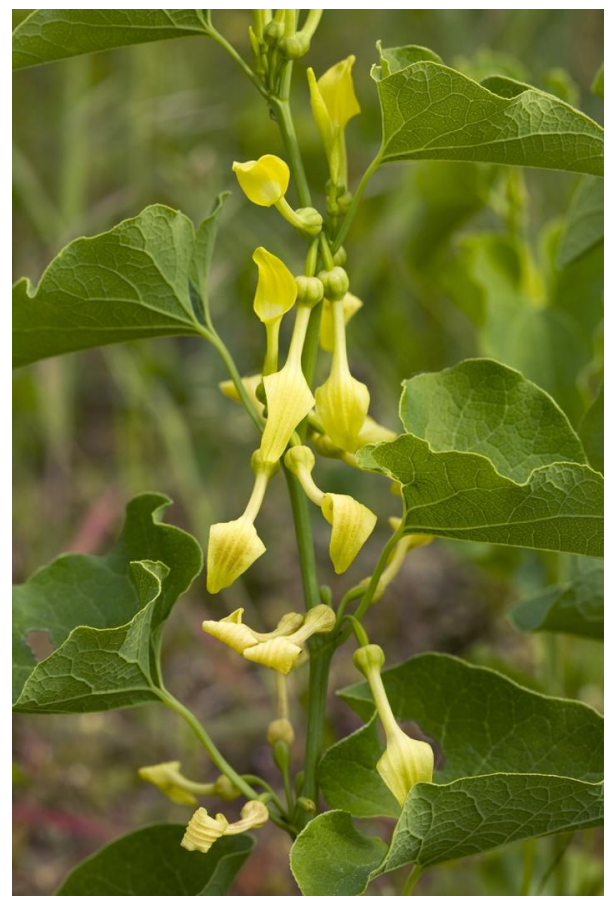

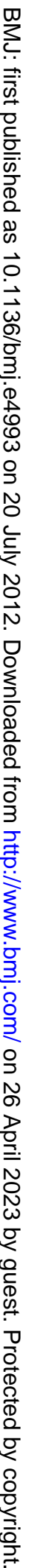

\section{Aristolochia clematitis}

[Image: BOB GIBBONS/SCIENCE PHOTO LIBRARY] 